Article

\title{
Preparation of Silica-Alumina Nanoparticles via Blast-Furnace Slag Dissolution in Low-Concentration Acetic Acid for Carbonation
}

\author{
Kyungsun Song, Wonbaek Kim, Sangwon Park, Jun-Hwan Bang, Jeongyun Kim \\ and Ji-Whan Ahn* \\ Korea Institute of Geoscience \& Mineral Resources (KIGAM), Gwahang-no 124, Yuseong-gu, \\ Daejeon 34132, Korea; kssong@kigam.re.kr (K.S.); wbkim@kigam.re.kr (W.K.); psw1231@kigam.re.kr (S.P.); \\ jhbang@kigam.re.kr (J.-H.B.); kooltz77@kigam.re.kr (J.K.) \\ * Correspondence: ahnjw@kigam.re.kr; Tel: + 82-42-868-3578
}

Received: 4 September 2017; Accepted: 25 October 2017; Published: 28 October 2017

\begin{abstract}
Blast-furnace slag (BFS) has been used as a feedstock for $\mathrm{CO}_{2}$ sequestration by indirect mineral carbonation to produce calcium carbonate precipitates and solid residues. The most-abundant elements in these residues, $\mathrm{Si}$ and $\mathrm{Al}$, are usually considered to be impurities that need to be removed in acid-dissolution processes involving BFS. The co-production of value-added materials from these residues is an attractive option for strengthening the economic competitiveness of mineral carbonation methods. In view of this, we separated the $\mathrm{Si}$ and $\mathrm{Al}$, as their hydrated forms, during the dissolution of $\mathrm{BFS}$ in acetic acid prior to carbonation. During the sol-gel processing of Si-Al nanoparticles, a catalyst is usually required during the hydrolysis and subsequent condensation processes. In this study, only condensation occurs because the low-concentrations of acetic acid used facilitate in-situ hydrolysis during the dissolution process. Aging was carried out not only to structurally arrange the $\mathrm{Si}$ and Al but also to oxidize the marginal Fe(II) to reddish Fe(III). Silica-alumina nanoparticles ( $78 \% \mathrm{Si}$ and $22 \% \mathrm{Al}$ ) were prepared by a simple sol-gel route at ambient pressure. These nanoparticles were amorphous and below $20 \mathrm{~nm}$ in size. Fourier-transform infrared (FT-IR) studies reveal that the nanoparticles consist of $\mathrm{Si}-\mathrm{O}-\mathrm{Si}$ and $\mathrm{Si}-\mathrm{O}-\mathrm{Al}$ bonds. ${ }^{27} \mathrm{Al}$ nuclear magnetic resonance (NMR) spectroscopy reveals a significant resonance corresponding to tetra-coordinated $\mathrm{Al}$ inside the particle framework.
\end{abstract}

Keywords: mineral carbonation; blast-furnace slag (BFS); acetic acid; silica-alumina nanoparticles

\section{Introduction}

Mineral carbonation is a technical option for the reduction of $\mathrm{CO}_{2}$ gas. It mimics natural weathering reactions where minerals containing divalent cations such as $\mathrm{Ca}$ or $\mathrm{Mg}$ slowly become converted into carbonates in the presence of $\mathrm{CO}_{2}$ [1]. Steel slag, an industrial byproduct, has been used as an attractive feedstock for $\mathrm{CO}_{2}$ sequestration because its chemical composition resembles those of silicate minerals and the steel industry is known to be one of the biggest emitters of anthropogenic $\mathrm{CO}_{2}$ [2]. Korea is the world's fifth largest producer of raw steel and about nine million tons of blast-furnace slag (BFS) is produced annually [3]. When the content of Ca in BFS (about $40 \mathrm{wt} \%$ as $\mathrm{CaO}$ ) is considered, its sequestration capacity is about 0.31 ton of $\mathrm{CO}_{2}$ per ton of BFS. Blast-furnace slag, one of the high-Ca-content steelmaking slags, is composed mainly of $\mathrm{Ca}$ as $\mathrm{CaO}(30-40 \mathrm{wt} \%)$, and $\mathrm{Si}$ as $\mathrm{SiO}_{2}(30-40 \mathrm{wt} \%)$, along with $\mathrm{Al}$ as $\mathrm{Al}_{2} \mathrm{O}_{3}(10-20 \mathrm{wt} \%)$.

Ever since acetic acid (a weak acid with a $\mathrm{pKa}=4.7$ ) was shown to be effective for the extraction of Ca from natural calcium silicates in mineral carbonation reactions [4], it has been used as a mild extraction agent for the selective extracting of Ca from BFS [5-10]. Most studies regarding the mineral carbonation of BFS are dedicated to the production of relatively pure $\mathrm{CaCO}_{3}$ following selective $\mathrm{Ca}$ 
dissolution. On the other hand, the other major element present in BFS, namely $\mathrm{Si}$, is considered to be a target material to be extracted as silica gel, along with other impurities during acid dissolution processes $[5,8,10]$. Temperatures above $50^{\circ} \mathrm{C}$ are recommended for the extraction of $\mathrm{Ca}$ and the removal of Si during the dissolution process [9].

The co-production of value-added materials is an attractive proposition for strengthening the economic competitiveness of mineral carbonation methods [10]. The selection of industrial waste as a staring material provides green routes for the synthesis of nanoparticles, considering the inefficiencies resulting from associated waste and/or reagents [11]. In view of this, it is interesting to find that silica and alumina nanoparticles in either single or mixed states are as important as more expensive materials used in the ceramics industry or as additives in the polymer industry, for example as conventional inorganic fillers. Furthermore, binary silica-alumina aerogels are among the most widely studied silica-based, mixed oxide aerogels [12-14].

The most widely applied method for the preparation of metal-oxide nanoparticles is the sol-gel process, which involves the hydrolysis and condensation of organic precursors in the presence of an acid or base as catalyst [14,15]. For silica-alumina nanoparticles, tetraethoxysilane (TEOS, $\left.\mathrm{Si}\left(\mathrm{OC}_{2} \mathrm{H}_{5}\right)_{4}\right)$ or tetramethoxysilane (TMOS, $\left.\mathrm{Si}\left(\mathrm{OCH}_{3}\right)_{4}\right)$, and aluminum-tri-sec-butoxide (ATSB, $\mathrm{Al}\left(\mathrm{C}_{2} \mathrm{H}_{5} \mathrm{CH}\left(\mathrm{CH}_{3}\right) \mathrm{O}_{3}\right)$ are generally used as precursors for silica and boehmite sol, respectively [16]. Previously, we demonstrated that Si-Al oxide composites could be prepared from BFS despite the use of uncontrolled coarse granules embedded with Fe(III) as a minor impurity [17]. It is possible to retard the formation of silica gel by manipulating the experimental parameters (i.e., acetic acid concentration, extracting temperature, and extracting time) during dissolution prior to the BFS carbonation process.

In this study, we evaluated the feasibility of producing pure silica-alumina nanoparticles via a simple indirect sol-gel route during BFS carbonation using acetic acid. We appraised the recovery of $\mathrm{Si}$ and $\mathrm{Al}$ in their dissolved hydrated forms on variations in extracting conditions. Aging was introduced not only to structurally arrange the $\mathrm{Si}$ and $\mathrm{Al}$, but also to oxidize soluble $\mathrm{Fe}$ (II) to reddish $\mathrm{Fe}(\mathrm{III})$. Shrinkage and stiffness of the gel was also controlled during both aging and drying steps, which are the most important in sol-gel processes [18]. The silica-alumina nanoparticles dried at ambient pressure were characterized using X-ray diffraction (XRD), Brunauer-Emmett-Teller (BET), Fourier-transform infrared (FT-IR), field-emission scanning electron microscopy (FE-SEM), field-emission transmission electron microscopy (FE-TEM), mercury porosimetry, and nuclear magnetic resonance (NMR) techniques.

\section{Experimental}

\subsection{Materials}

Granulated BFS was obtained from a steel making company in Pohang, Korea [17]. The sample was crushed and powdered to obtain particles ranging from 75 to $300 \mu \mathrm{m}$ in size. Based on the analysis of its chemical composition, approximately $95 \mathrm{wt} \%$ of the BFS consists of three major elements: Ca (43.4 dry wt $\%$ as $\mathrm{CaO}$ ), $\mathrm{Si}\left(37.7\right.$ dry wt $\%$ as $\mathrm{SiO}_{2}$ ), and $\mathrm{Al}\left(13.4\right.$ dry wt $\%$ as $\left.\mathrm{Al}_{2} \mathrm{O}_{3}\right)$. Other impurities were determined to be mainly $\mathrm{MgO}$ (3.82 dry wt \%) and $\mathrm{Fe}_{2} \mathrm{O}_{3}$ (1.33 dry wt \%).

\subsection{Extraction Procedure}

In extraction experiments using acetic acid (Sigma-Aldrich, St. Louis, MO, USA; ACS grade), $20 \mathrm{~g} / \mathrm{L}$ of BFS was used to compare the amounts of dissolved elements in varying concentrations $(0-30 \% v / v)$ of acetic acid after stirring at room temperature for $1 \mathrm{~h}$. The solution temperature was set to around $30^{\circ} \mathrm{C}$, which was easily obtained at room temperature because the dissolution of BFS in acetic acid is exothermic. A control extraction experiment was conducted in deionized water (purified using a Milli-Q $18 \mathrm{M} \Omega$-cm system, Millipore Corp., Milford, MA, USA) using $20 \mathrm{~g} / \mathrm{L}$ of BFS. The relationship between the amount of each extracted element and the acetic acid concentration was examined at $30{ }^{\circ} \mathrm{C}$ using 2 and $5 \mathrm{vol} \%$ acetic acid solutions at solid/liquid ratios of 20 and $50 \mathrm{~g} / \mathrm{L}$, 
respectively. All extraction experiments were performed in a 1-L three-necked double-jacketed Pyrex glass reactor. A mechanical stirrer (WiseStir ${ }^{\circledR}$ HT120DX, Daihan Scientific Co. Ltd., Wonju, Korea) was installed at the center of the reactor and used to mix the slurry at $500 \mathrm{rpm}$. The temperature of the reactor was maintained using an external circulating water bath (RW-1025, JEIL TECH, Daejeon, Korea). Filtration was performed with a $0.2 \mu \mathrm{m}$ membrane filter (mixed cellulose ester, ADVANTEC). A $1 \mathrm{~mL}$ filtered sample was acidified with instrumental-grade $\mathrm{HNO}_{3}$ to $5 \%(v / v)$ in order to determine the concentrations of the five major elements present $(\mathrm{Ca}, \mathrm{Si}, \mathrm{Mg}, \mathrm{Fe}$, and $\mathrm{Al})$ using inductively coupled plasma optical emission spectrometry (ICP-OES; Optima 5300DV, Perkin Elmer, Waltham, MA, USA). The $\mathrm{pH}$ and temperature of the mixture were monitored using a $\mathrm{pH}$ meter (Orion 410A, Thermo Scientific, Waltham, MA, USA). All experiments were performed in triplicate, and variations between results were found to be less than $5 \%$.

\subsection{Synthesis of Silica-Alumna Composites}

Our previous study demonstrated that carbonation could be performed via two methods using the extracted solution: One was to carbonate after separating the silica-rich gel, while the other was to carbonate all the leachates [17]. In this study, during the former process, impurities containing dissolved divalent cations such as $\mathrm{Ca}$ and $\mathrm{Mg}$ were elaborated to remain as much as possible in solution for the preparation of pure Si-Al nanoparticles. A more detailed carbonation conditions are described in our previous work [17].

Based on preliminary extraction experiments, the extracted solution from $20 \mathrm{~g} / \mathrm{L}$ of BFS using $5 \%$ acetic acid was chosen as the source of $\mathrm{Si}$ and $\mathrm{Al}$ for the silica-alumina nanoparticles. The filtered solution, prepared as described in Section 2.2., was stirred at $500 \mathrm{rpm}$ at $60{ }^{\circ} \mathrm{C}$ for $4 \mathrm{~h}$ to obtain a silica-alumina hydrogel. The initial $\mathrm{pH}$ of the solution was 4.3 and the amount of filtered solid residue was about $0.09 \mathrm{~g}$ (below $0.01 \mathrm{wt} \%$ ) after drying overnight at $80^{\circ} \mathrm{C}$. Fe(II) is soluble, mobile in water, and readily oxidized to reddish Fe(III) in air [19]. The white hydrogel was allowed to stand for $24 \mathrm{~h}$ at $50{ }^{\circ} \mathrm{C}$ for both condensation and the oxidation of marginal amounts of dissolved Fe(II) to Fe(III) during the incorporation of aluminum into the silicate network of nanoparticles. As expected, the clear upper layer (solution) became brownish upon Fe(III) elution and was separated for the carbonation process by centrifugation. In addition, to wash off any remaining soluble divalent cations such as Ca or $\mathrm{Mg}, 500 \mathrm{~mL}$ of hot water was mixed with the hydrogel and stirred for 2-3 min, after which the mixture was allowed to settle for $24 \mathrm{~h}$ at $50{ }^{\circ} \mathrm{C}$. The slurry was then washed by centrifugation with distilled water (5x) followed by ethanol (Samchun Chemical, GR grade, Seoul, Korea) (5x). The solution was decanted and the remaining gel was dried overnight at $50{ }^{\circ} \mathrm{C}$ at atmospheric pressure.

Calcium, silica, and alumina are the major components of BFS, and divalent cations (mainly $\mathrm{Ca}$ ) react with $\mathrm{CO}_{2}$ gas to form carbonate minerals during $\mathrm{CO}_{2}$ mineralization. It is important to decide which of the products (calcium carbonate or silica-alumina residues) from the carbonation process is of greater value. In this study, the feasibility of co-producing Si-Al nanoparticles (the more valuable material) during the BFS mineral carbonation process was examined.

It is not possible to separate the desired material from the BFS solid impurities once gelation occurs following dissolution. Fortunately, our recent study revealed that the Si-Al gel precursor can be separated from the impurities by exploiting an extracted solution containing hydrated Si and Al ions [17]. The dissolved hydrated $\mathrm{Si}$ and $\mathrm{Al}$ ions were then precipitated to form pure Si-Al nanoparticles through a sol-gel route. A typical sol-gel process for silica/alumina particles consists of four major stages: hydrolysis (i.e., formation of $\mathrm{Si}(\mathrm{OH})_{4}$ or $\left.\mathrm{Al}(\mathrm{OH})_{3}\right)$, condensation (i.e., formation of $\mathrm{Si}-\mathrm{O}-\mathrm{Si}$ or $\mathrm{Si}-\mathrm{O}-\mathrm{Al})$, aging, and drying. A flowchart for the formation of pure Si-Al nanoparticles from BFS is provided in Figure 1. 


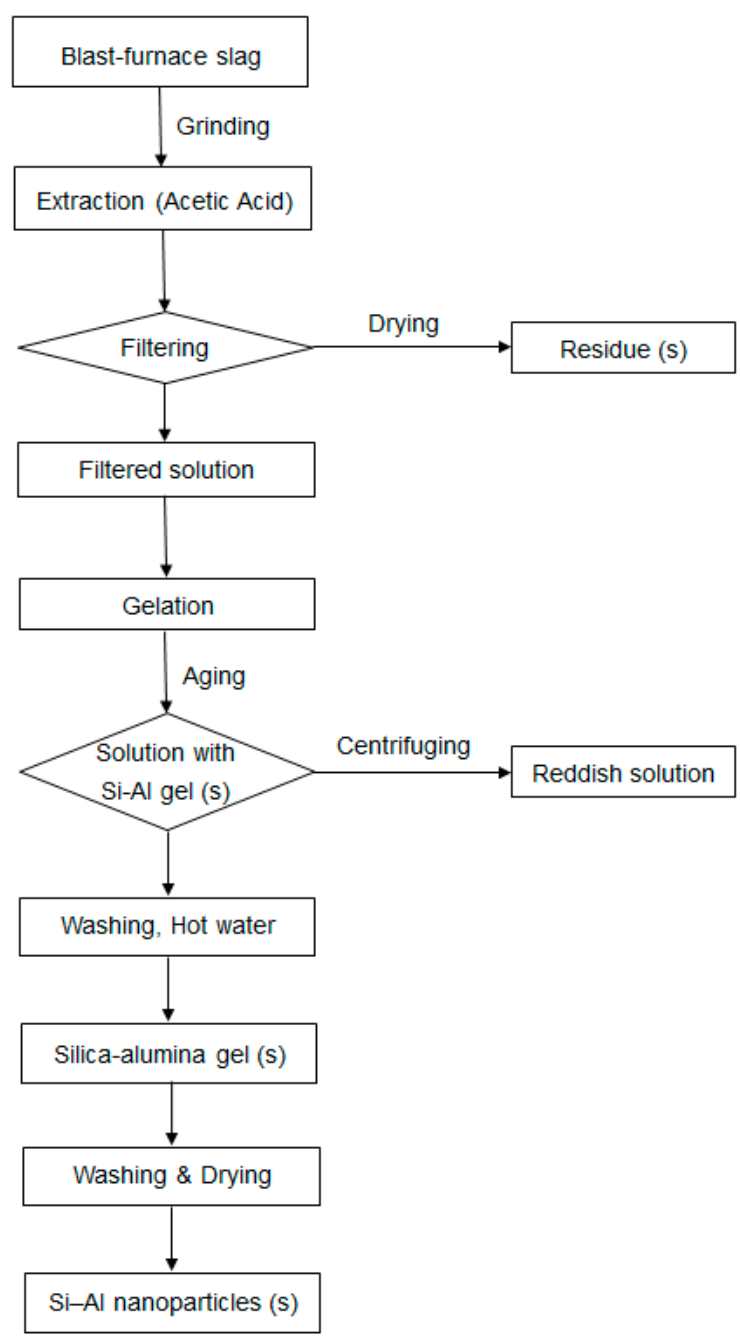

Figure 1. Flowchart for the synthesis of silica-alumina nanoparticles from blast-furnace slag.

\subsection{Characterization of the Silica-Alumina Composites}

The amounts of $\mathrm{Si}$ and $\mathrm{Al}$ in the silica-alumina nanoparticles were determined using ICP-OES from the difference in the concentrations of dissolved metals after extracting and aging. The nanoparticles were characterized by FE-TEM (Tecnai G ${ }^{2}$ F30 S-Twin, Philips-FEI, Eindhoven, Netherlands) equipped with selected-area electron diffraction (SAED) and energy-dispersed X-ray (EDX) spectrometers. The microscope was operated at $300 \mathrm{kV}$ at a point resolution of $0.2 \mathrm{~nm}$. The TEM specimen was ultrasonically dispersed in ethanol after which a drop of the dispersion was placed on a holey carbon grid.

The specific surface area was measured by $\mathrm{N}_{2}$ adsorption/desorption at $77 \mathrm{~K}$ using the BET method using a Quadrasorb SI surface area analyzer (Quantachrome, Boynton Beach, FL, USA), and the pore-size distribution of the nanoparticles was determined using an AutoPore IV 9500 V1.05 mercury porosimeter (Micromeritics, Norcross, GR, USA).

The surface morphology was examined by FE-SEM (SU8230, Hitachi, Tokyo, Japan) equipped with EDX at KBSI (Korea Basic Science Institute, Jeonju Center). The samples were cast onto carbon tape and coated with a thin layer of platinum to eliminate the effect of charging. The FE-SEM and EDX analysis systems were operated at 10 and $15 \mathrm{kV}$, respectively.

The structures of the crystalline minerals were examined by XRD (X'pert MPD, Philips Analytical, Eindhoven, Netherlands) over the $10^{\circ}-65^{\circ} 2 \theta$ range using $\mathrm{Cu} \mathrm{K} \alpha$ radiation in step-scan mode due to 
the low signal/noise ratio of the amorphous phase; the tube voltage was $45 \mathrm{kV}$, the tube current was $200 \mathrm{~mA}$, and $0.01^{\circ}$ steps of $1 \mathrm{~s}$ duration were employed.

The functional-group composition was examined using FT-IR spectroscopy (Prestige-21; Shimadzu Corp., Tokyo, Japan) equipped with an attenuated total reflectance ATR system (MIRacle A) and a ZnSe lens. Twenty scans were performed in the $400-4000 \mathrm{~cm}^{-1}$ region, with a spectral resolution of $4 \mathrm{~cm}^{-1}$, after appropriate background subtraction. ${ }^{27} \mathrm{Al}$ solid-state magic-angle spinning (MAS, Varian, Palo Alto, CA, USA) nuclear magnetic resonance (NMR, Varian, Palo Alto, CA, USA) spectra were acquired in an $11.7 \mathrm{~T}$ ultrashielded superconducting magnet using a Varian Unity Inova $500 \mathrm{MHz}$ spectrometer equipped with a $1.2 \mathrm{~mm}$ Chemagnetics MAS probe head at a sample rotation rate of $20 \mathrm{kHz}$ at KBSI (Daejeon Center).

\section{Results and Discussion}

\subsection{Extraction of Silica and Alumina from BFS}

The solution obtained by extracting BFS using acetic acid provides silica-alumina-aerogel precursors. Since in-situ hydrolysis occurs in acetic acid solution, only the condensation reactions need to be considered. Furthermore, the use of low-concentrations of acetic acid is beneficial from an economic perspective during the carbonation process, because swings to high $\mathrm{pH}$ are required for $\mathrm{CO}_{2}$ sorption. In this study, the effect of the acetic acid concentration (0-30 vol \%) on the dissolution of $\mathrm{Si}$ and $\mathrm{Al}$ was investigated at room temperature for $1 \mathrm{~h}$ using $20 \mathrm{~g} / \mathrm{L}$ of BFS. As shown in Figure 2, $\mathrm{Si}$ and $\mathrm{Al}$ hardly dissolve in water, but maximum dissolution efficiencies for $\mathrm{Si}$ and $\mathrm{Al}$ in dilute acetic acid were $96 \%(0.12 \mathrm{~mol} / \mathrm{L})$ and $87 \%(0.05 \mathrm{~mol} / \mathrm{L})$, respectively. We noted that the amount of dissolved Si decreased with increasing acetic acid concentration due to acceleration of the gelation process.

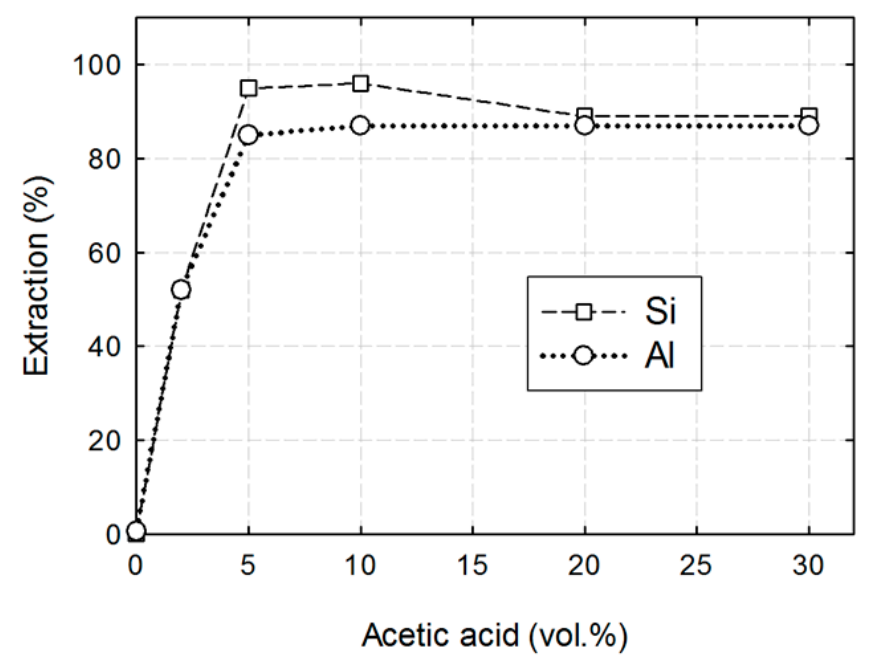

Figure 2. Extracted levels of $\mathrm{Si}$ and $\mathrm{Al}$ as functions of acetic acid concentration.

To determine the stoichiometric amount of acetic acid required for $\mathrm{Si}$ and $\mathrm{Al}$ dissolution, solid-to-liquid ratios were varied from 20 to $50 \mathrm{~g} / \mathrm{L}$. Figure 3 displays the relationship between the concentration of acetic acid and the concentrations of dissolved $\mathrm{Si}$ and Al. The dissolution of each element displays a linear dependence on acetic acid concentration, with $R^{2}$ values in excess of 0.9999 . The slopes of the $\mathrm{Si}$ and $\mathrm{Al}$ plots are 0.20 and 0.085 , respectively. 


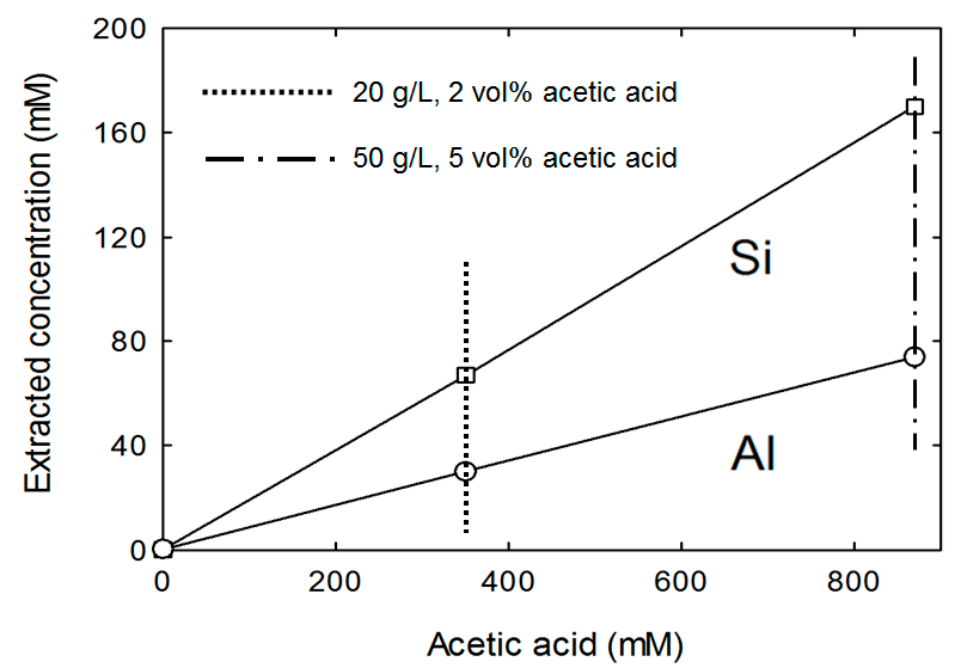

Figure 3. Concentrations of extracted $\mathrm{Si}$ and $\mathrm{Al}$ as functions of acetic acid concentration.

\subsection{Preparation of the Silica-Alumina Nanoparticles}

We confirmed that almost all of the BFS (Figure 4a) dissolved in the acetic acid because the amount of filtered solid residue (dark brown color) was less than $0.01 \mathrm{wt} \%$. The filtrate from the BFS slurry was transparent during the early stage of the preparation process. When the temperature was increased to $60{ }^{\circ} \mathrm{C}$, a white Si-rich sol formed in the solution which rapidly turned into a gel (Figure $4 \mathrm{~b}$ ). The solution containing the $\mathrm{Si}-\mathrm{Al}$ gel was allowed to settled during the aging process, during which nucleation and Si-Al-nanoparticle growth occurred, and marginal amounts of dissolved Fe(II) were oxidized to reddish $\mathrm{Fe}(\mathrm{III})$ (Figure 4c). After two $24 \mathrm{~h}$ aging steps at $50{ }^{\circ} \mathrm{C}$ (in aqueous acetic acid and warm water) and a washing step, whitish nanoparticles were formed (Figure $4 \mathrm{~d}$ ) that were composed of $\mathrm{Si}(78 \mathrm{~mol} \%)$ and $\mathrm{Al}(22 \mathrm{~mol} \%)$. Consequently, the final recoveries of $\mathrm{Si}$ and $\mathrm{Al}$, in the form of silica-alumina nanoparticles, from BFS were 85 and $57 \mathrm{~mol} \%$, respectively.

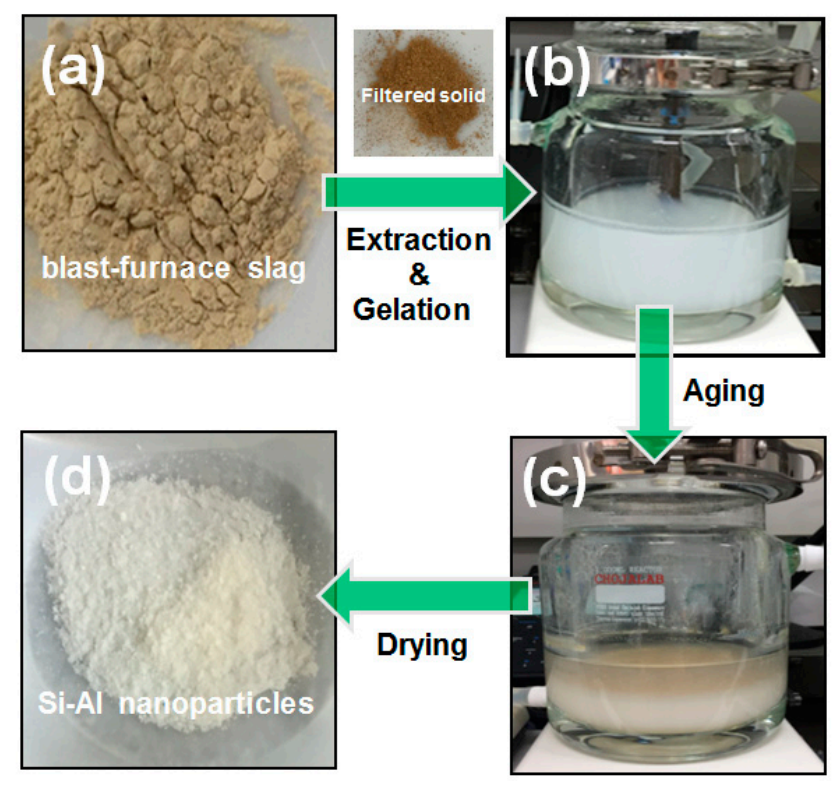

Figure 4. Photographic images depicting the synthesis of the silica-alumina nanoparticles: (a) blast-furnace slag; (b) gel-rich solution after extracting; (c) solution after aging; and (d) nanoparticles after drying. 


\subsection{Characterization of the Si-Al Nanoparticles}

After subcritical drying under atmospheric pressure, TEM equipped with EDS/SAED was used to examine the particle morphology, crystalline structure, and the elemental distributions of $\mathrm{Si}$ and Al. Figure 5 depicts a TEM micrograph of the nanoparticles and the corresponding $\mathrm{O}, \mathrm{Si}$, and Al EDX maps. Based on the TEM image, the particles appear to be aggregated. The EDX images reveal uniformly distributed aluminum in the silica network, indicating that a homogeneous Si-Al-nanoparticle composite had formed.
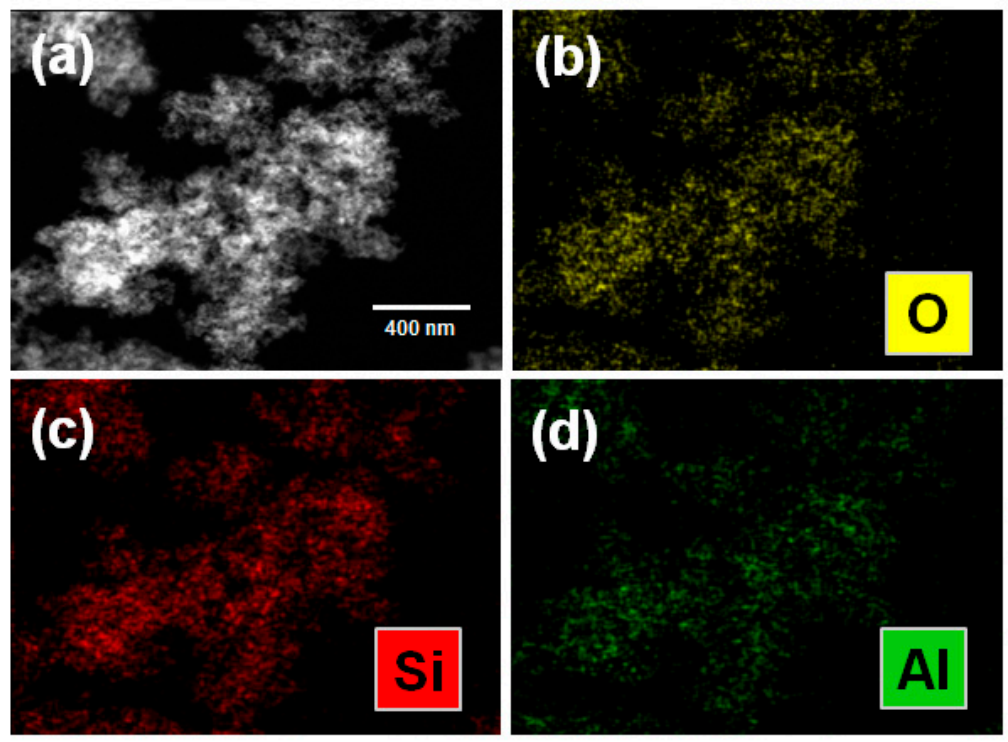

Figure 5. (a) FE-TEM image of the silica-alumina nanoparticles; and the corresponding: (b) O; (c) Si; and (d) Al EDX maps.

Based on the SAED results, the nanoparticles were determined to be amorphous (not shown). The amorphous nature of the nanoparticles is more evident by X-ray diffraction using the step-scan mode. Figure 6 displays the X-ray diffraction patterns of the nanoparticles together with those of BFS. The XRD pattern of the Si-Al nanoparticles exhibits a single broad amorphous peak. The center of this broad peak is positioned at a lower angle compared to that of BFS; at around $24^{\circ}$ this peak is at a similar position to that previously reported for silica-alumina nanocomposites [20].

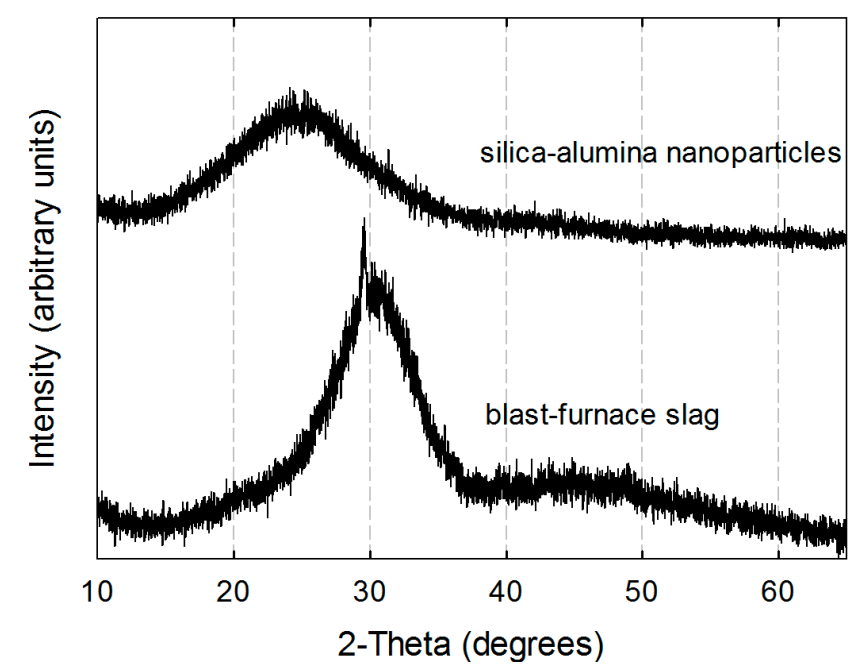

Figure 6. XRD patterns of blast-furnace slag and the silica-alumina nanoparticles. 
Figure 7 compares the TEM and SEM images of the Si-Al nanoparticles in order to estimate the approximate sizes of the primary particles and the extent of aggregation. Based on the SEM image, the primary particles are determined to be less than $20 \mathrm{~nm}$ in size, but large secondary particles are also apparent and appear to be aggregates of the spherical primary particles. Moreover, since the secondary particles are not well-dispersed, it is difficult to determine the sizes of these particles.
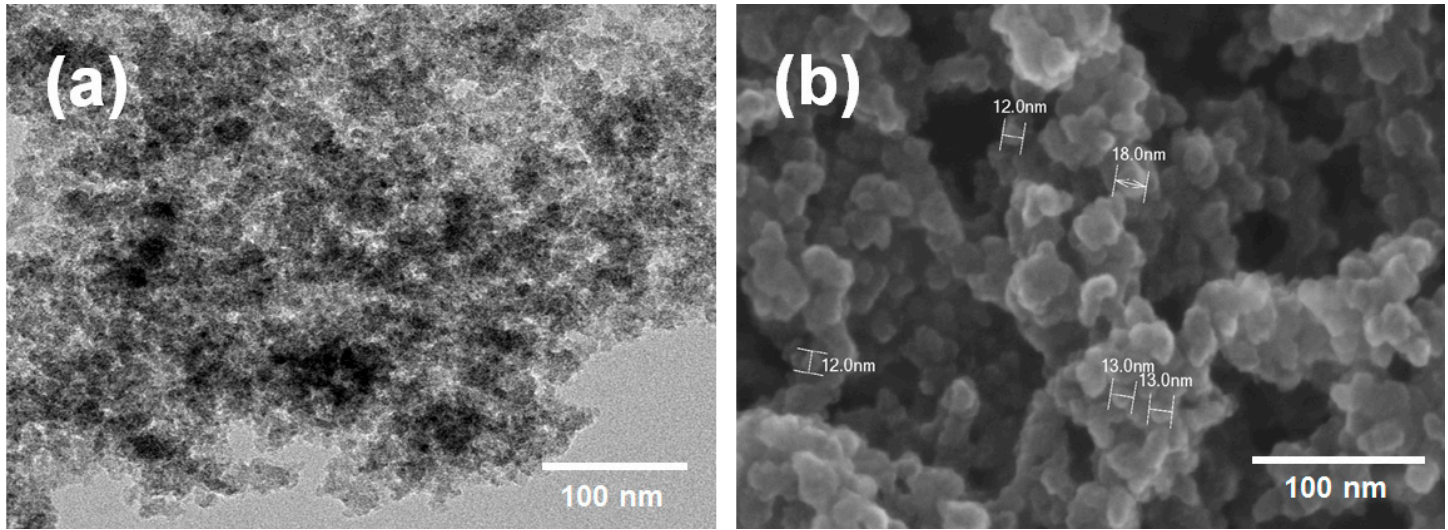

Figure 7. (a) FE-TEM; and (b) FE-SEM images of the silica-alumina nanoparticles at the $100 \mathrm{~nm}$ level.

The specific surface area of our nanoparticles was determined to be $264 \mathrm{~m}^{2} / \mathrm{g}$, which is comparable to that of nanoparticles $(25 \mathrm{~mol} \% \mathrm{Al}$ ) synthesized using an organic precursor [18]. These particles exhibit a bimodal pore-size distribution, as displayed in Figure 8. A distribution centered at $12 \mathrm{~nm}$ and another centered at around $25 \mathrm{~nm}$ are observed. The broad tail observed for the latter peak is ascribed to the packing or aggregation of small primary particles.

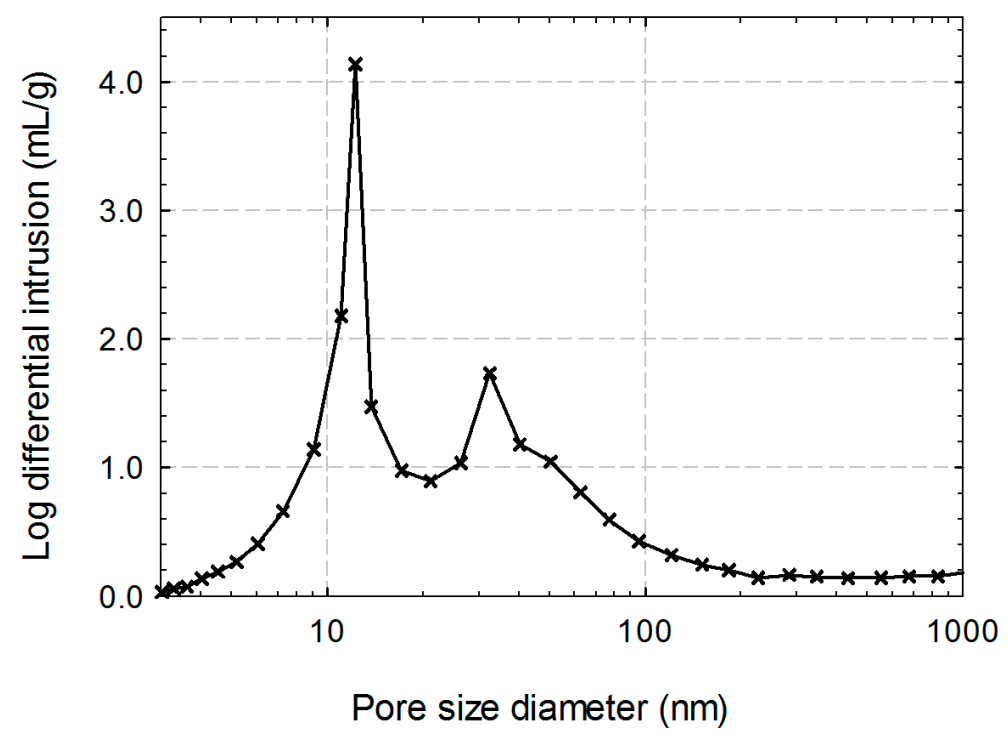

Figure 8. Pore size distribution of the silica-alumina nanoparticles.

Figure 9 compares the infrared spectrum of the silica-alumina nanoparticles with that of BFS. In BFS, a characteristic peak at $900 \mathrm{~cm}^{-1}$ is evident, which is assigned to the asymmetric and symmetric $\mathrm{Si}-\mathrm{O}$ stretching vibrations [17]. In the silica-alumina nanoparticles, a characteristic $\mathrm{Si}-\mathrm{O}-\mathrm{Si}$ vibration peak at $1040 \mathrm{~cm}^{-1}$ is clearly evident, along with shoulders on both the higher and lower sides of the band that indicate the presence of $\mathrm{Si}-\mathrm{O}-\mathrm{Al}$ bonds $[18,21]$. The peak at $3300 \mathrm{~cm}^{-1}$ is ascribed to $\mathrm{OH}$ vibrations resulting from the hydroxylation of the nanoparticle surfaces by absorbed water, which may 
catalyze the aggregation of the primary particles. The aluminum ions that form $\mathrm{Si}-\mathrm{O}-\mathrm{Al}$ bonds can be four- or six-coordinated. To shed further light on the binding state of $\mathrm{Al}$ in the Si network structure, complementary NMR studies were carried out (Figure 10).

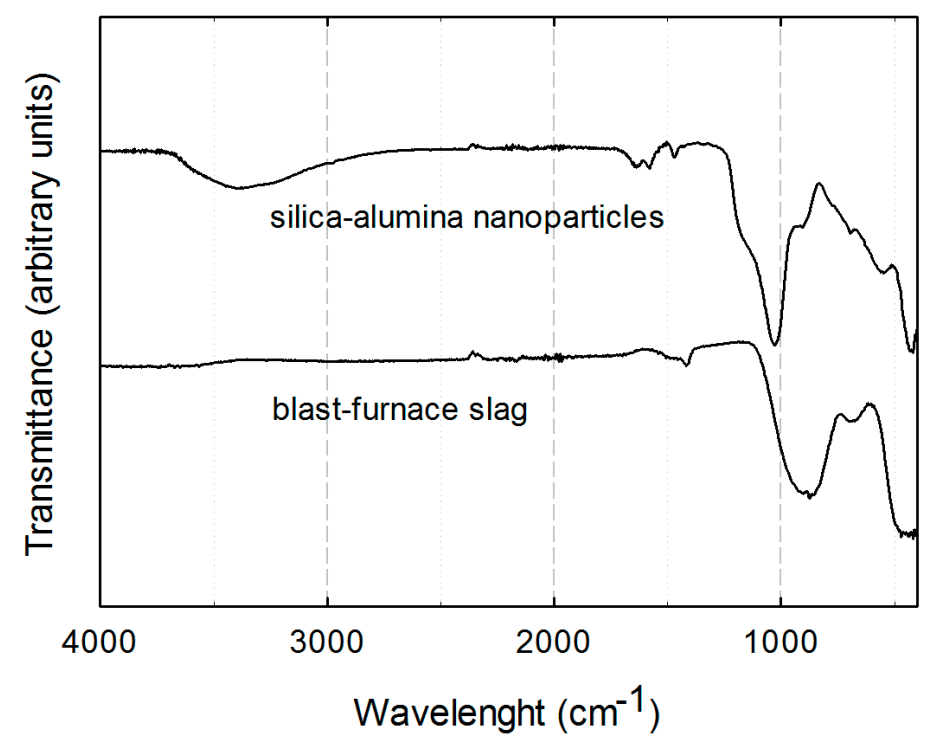

Figure 9. FT-IR spectra of blast-furnace slag and the silica-alumina nanoparticles.

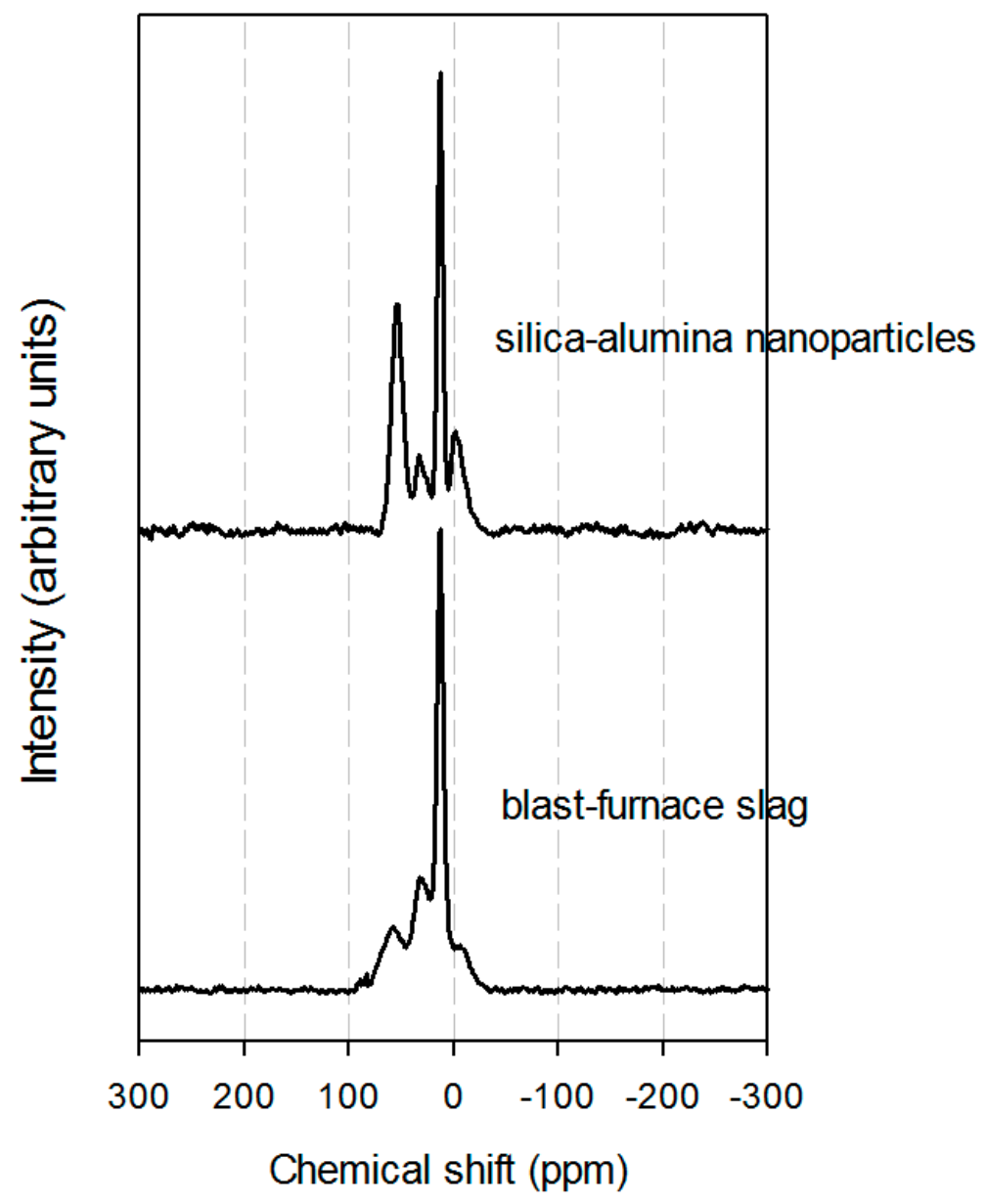

Figure 10. ${ }^{27} \mathrm{Al}$ MAS-NMR spectra of blast-furnace slag and the silica-alumina nanoparticles. 
The aluminum ions are mainly incorporated into the silica framework in tetra-, penta-, or hexacoordinated forms. Hexa-coordinated $\mathrm{Al}$ atoms are incorporated at considerable levels on the surface of the silica framework, while the tetrahedrally coordinated ions are mainly incorporated inside, as part of the network. ${ }^{27} \mathrm{Al}$ MAS-NMR spectra provide valuable information about the coordinations and local structures of the aluminum sites in silica-alumina compounds. In general, ${ }^{27} \mathrm{Al}$ MAS-NMR spectra consist of three well-defined peaks: a peak at 0-16 ppm attributed to octahedrally coordinated $\mathrm{AlO}_{6}$, a peak at 55-80 ppm attributed to tetrahedrally coordinated $\mathrm{AlO}_{4}$, and a peak at 25-35 ppm attributed to five-fold coordinated $\mathrm{AlO}_{5}$ [22]. Figure 10 displays the ${ }^{27} \mathrm{Al}$ MAS NMR spectra of BFS and the silica-alumina nanoparticles, which reveal that BFS is mainly composed of octahedral and distorted tetrahedral aluminum sites. On the other hand, the tetrahedral peak at $54 \mathrm{ppm}$ is more intense and sharper in the spectrum of the nanoparticles. A resonance corresponding to penta-coordinated $\mathrm{Al}$, at $32 \mathrm{ppm}$, is clearly observable; this peak has been reported to be commonly observed in oxides formed by sol-gel processes [23]. These results confirm that elemental aluminum was incorporated into the silica framework affecting its tetrahedral configuration.

\subsection{The Merits of the Current Process}

Conventionally, blast-furnace slag (BFS) has been used for $\mathrm{CO}_{2}$ sequestration by mineral carbonation to produce calcium carbonate precipitates and solid residues. Consequently, most studies on the mineral carbonation of BFS have focused on selective Ca dissolution and the production of relatively pure $\mathrm{CaCO}_{3}$. Solid residues, including $\mathrm{Si}$, were regarded as impurities $[5,6]$. Calcium carbonate in this process is a by-product in the sense that it is produced at the end of the process. Even though the calcium carbonate precipitate is a by-product, it, unfortunately, has little economic value.

One of the objectives of this study was the establishment of a route for controlling the aggregation of silica through the preparation of silica compounds that reduce leaching residues; discarding the solid residues has associated costs. The polymerization of silica is the main drawback that significantly affects mineral carbonation using acid-leaching processes because the formation of silica gel introduces challenges for solid-liquid separation. In general, a high concentration of acetic acid (i.e., $33 \mathrm{wt} \%$ ) and a temperature of $70{ }^{\circ} \mathrm{C}$ have been used for the removal of Si-rich gels and the extraction of Ca. In this study, our objective was achieved technically through the use of a low concentration of acetic acid (5\%) at ambient temperatures. This procedural change makes the process somewhat more economical.

The cost effectiveness of the process was additionally improved by developing a route for the production of $\mathrm{Si}-\mathrm{Al}$ nanoparticles; this nanoparticle product, by definition, is a co-product that is produced along with the main product and is of comparable importance to it [24]. The Si-Al nanoparticles in the current study belong to this category. Binary $\mathrm{SiO}_{2}-\mathrm{Al}_{2} \mathrm{O}_{3}$ compositions have traditionally been used in the ceramics industry [16]. In addition to these applications, they have also been used as important additives in the polymer industry in either discrete or mixed states (e.g., as inorganic fillers) [14].

For the BFS-carbonation process to go beyond the environmental justification of capturing and sequestering $\mathrm{CO}_{2}$ emissions, the economics of value-added products, such as by-product and co-product, need to be considered more rigorously. It is clear that the economy of the current process can be improved by increasing its value as a revenue-generating resource, and by reducing the amount of non-revenue-generating material produced, as discussed by Hitch et al. [24].

\section{Conclusions}

$\mathrm{Si}-\mathrm{Al}$ nanoparticles were co-produced during the indirect mineral carbonation of blast-furnace slag (BFS) using low-concentration acetic acid. In this study, Si and Al were separated as their hydrated forms during the dissolution process using acetic acid prior to BFS carbonation. Only condensation reactions are required for the synthesis of silica-alumina nanoparticles by the sol-gel process because the low concentrations of acetic acid allow for in-situ hydrolysis. Aging was introduced not only to structurally arrange the $\mathrm{Si}$ and $\mathrm{Al}$, but also to oxidize the marginal $\mathrm{Fe}(\mathrm{II})$ to reddish $\mathrm{Fe}(\mathrm{III})$. 
Silica-alumina nanoparticles $(78 \% \mathrm{Si}$ and $22 \% \mathrm{Al})$ were prepared via a simple sol-gel route under ambient pressure. X-ray diffraction reveals that the Si-Al nanoparticles are amorphous with particles less than $20 \mathrm{~nm}$ in size, according to TEM and FE-SEM. FT-IR and NMR studies reveal that alumina is incorporated into a silicate-crystal framework. FT-IR reveals that the nanoparticles are constructed from $\mathrm{Si}-\mathrm{O}-\mathrm{Si}$ and $\mathrm{Si}-\mathrm{O}-\mathrm{Al}$ bonds. The ${ }^{27} \mathrm{Al}$ MAS-NMR spectrum exhibits a characteristic penta-coordinated signal generally detected in oxides prepared by sol-gel methods, along with a significant resonance that corresponds to tetra-coordinated $\mathrm{Al}$ present inside the framework. We believe that the co-production of value-added materials helps to make the mineral carbonation method more economically feasible.

Acknowledgments: This work was supported by a grant from the R\&D Center for Valuable Recycling (Global-Top R\&BD Program) of the Ministry of Environment (Project No.: 2016002230004) of the Korean government.

Author Contributions: Kyungsun Song and Wonbaek Kim designed and managed the study; Sangwon Park, Jun-Hwan Bang, Jeongyun Kim performed experiments and analyzed the data; Ji-Whan Ahn conceptualized and interpreted data.

Conflicts of Interest: The authors declare no conflicts of interest.

\section{References}

1. Seifritz, W. $\mathrm{CO}_{2}$ disposal by means of silicates. Nature 1990, 345, 486. [CrossRef]

2. Huijgen, W.J.J.; Comans, R.N.J. Mineral $\mathrm{CO}_{2}$ sequestration by steel slag carbonation. Environ. Sci. Technol. 2005, 39, 9676-9682. [CrossRef] [PubMed]

3. Korean iron and steel association. Steel Statistics. Available online: http://www.kosa.or.kr (accessed on 1 September 2017).

4. Kakizawa, M.; Yamasaki, A.; Yanagisawa, Y. A new $\mathrm{CO}_{2}$ disposal process via artificial weathering of calcium silicate accelerated by acetic acid. Energy 2001, 26, 341-354. [CrossRef]

5. Teir, S.; Eloneva, S.; Fogelholm, C.J.; Zevenhoven, R. Dissolution of steelmaking slags in acetic acid for precipitated calcium carbonate production. Energy 2007, 32, 528-539. [CrossRef]

6. Bao, W.; Li, H.; Zhang, Y. Selective leaching of steelmaking slag for indirect $\mathrm{CO}_{2}$ mineral sequestration. Eng. Chem. Res. 2010, 49, 2055-2063. [CrossRef]

7. Chiang, Y.W.; Santos, R.M.; Elsen, J.; Meesschaert, B.; Martens, J.A.; Van Gerven, T. Towards zero-waste mineral carbon sequestration via two-way valorization of ironmaking slag. Chem. Eng. J. 2014, 249, 260-269. [CrossRef]

8. De Crom, K.; Chiang, Y.W.; Van Gerven, T.; Santos, R.M. Purification of slag-derived leachate and selective carbonation for high-quality precipitated calcium carbonate synthesis. Chem. Eng. Res. Des. 2015, 104, 180-190. [CrossRef]

9. Eloneva, S.; Teir, S.; Salminen, J.; Fogelholm, C.J.; Zevenhoven, R. Fixation of $\mathrm{CO}_{2}$ by carbonating calcium derived from blast furnace slag. Energy 2008, 33, 1461-1467. [CrossRef]

10. Eloneva, S.; Teir, S.; Salminen, J.; Fogelholm, C.J.; Zevenhoven, R. Steel converter slag as a raw material for precipitation of pure calcium carbonate. Ind. Eng. Chem. Res. 2008, 47, 7104-7111. [CrossRef]

11. Reid, B.T.; Reed, S.M. Improved methods for evaluating the environmental impact of nanoparticle synthesis. Green Chem. 2016, 18, 4263-4269. [CrossRef] [PubMed]

12. Gun'ko, V.M.; Ilkiv, V.Y.; Zaulychnyy, Y.V.; Zarko, V.I.; Pakhlov, E.M.; Karpetz, M.V. Structural features of fumed silica and alumina alone, blend powders and fumed binary systems. J. Non-Cryst. Solids 2014, 403, 30-37. [CrossRef]

13. Jankeviciute, A.; Károly, Z.; Tarakina, N.V.; Szépvölgyi, J.; Kareiva, A. Synthesis and characterization of spherical amorphous alumo-silicate nanoparticles using RF thermal plasma method. J. Non-Cryst. Solids 2013, 359, 9-14. [CrossRef]

14. Rahman, I.A.; Padavettan, V. Synthesis of silica nanoparticles by sol-gel: Size-dependent properties, surface modification, and applications in silica-polymer nanocomposites-A review. J. Nanomater. 2012, 2012, 1-15. [CrossRef]

15. Sharma, R.K.; Sharma, S.; Dutta, S.; Zboril, R.; Gawande, M.B. Silica-nanosphere-based organic-inorganic hybrid nanomaterials: Synthesis, functionalization and applications in catalysis. Green Chem. 2015, 17, 3207-3230. [CrossRef] 
16. Kang, S.; Kim, B.I.; Kim, C.Y.; Lee, J.K.; Bae, D.S. Synthesis and microstructure of $\mathrm{Al}_{2} \mathrm{O}_{3}-\mathrm{SiO}_{2}$ nanoparticles by a sol-gel processing. Solid State Phenom. 2007, 124-126, 679-682. [CrossRef]

17. Song, K.; Park, S.; Kim, W.; Jeon, C.; Ahn, J.W. Effects of experimental parameters on the extraction of silica and carbonation of blast furnace slag at atmospheric pressure in low-concentration acetic acid. Metals 2017, 7, 199. [CrossRef]

18. Aravind, P.R.; Mukundan, P.; Krishna Pillai, P.; Warrier, K.G.K. Mesoporous silica-alumina aerogels with high thermal pore stability through hybrid sol-gel route followed by subcritical drying. Microporous Mesoporous Mater. 2006, 96, 14-20. [CrossRef]

19. Davison, W.; Seed, G. The kinetics of the oxidation of ferrous iron in synthetic and natural waters. Geochim. Cosmochim. Acta 1983, 47, 67-79. [CrossRef]

20. Saber, O.; Gobara, H.M. Optimization of silica content in alumina-silica nanocomposites to achieve high catalytic dehydrogenation activity of supported Pt catalyst. Egypt. J. Pet. 2014, 23, 445-454. [CrossRef]

21. Jiao, D.; Zheng, S.; Wang, Y.; Guan, R.; Cao, B. The tribology properties of alumina/silica composite nanoparticles as lubricant additives. Appl. Surf. Sci. 2011, 257, 5720-5725. [CrossRef]

22. Singh, P.S.; Trigg, M.; Burgar, I.; Bastow, T. Geopolymer formation processes at room temperature studied by ${ }^{29} \mathrm{Si}$ and ${ }^{27}$ Al MAS-NMR. Mater. Sci. Eng. A 2005, 396, 392-402. [CrossRef]

23. Smith, M.E. Application of ${ }^{27} \mathrm{Al}$ NMR techniques to structure determination in solids. Appl. Magn. Reson. 1993, 4, 1-64. [CrossRef]

24. Hitch, M.; Ballantyne, S.M.; Hindle, S.R. Revaluing mine waste rock for carbon capture and storage. Int. J. Min. Reclam. Environ. 2010, 24, 64-79. [CrossRef]

(C) 2017 by the authors. Licensee MDPI, Basel, Switzerland. This article is an open access article distributed under the terms and conditions of the Creative Commons Attribution (CC BY) license (http:/ / creativecommons.org/licenses/by/4.0/). 